\title{
A pesquisa em Educação Ambiental: uma análise dos trabalhos apresentados na ANPED, ANPPAS e EPEA de 2001 a 2006
}

\author{
Isabel Cristina de Moura Carvalho ${ }^{1}$ \\ Leticia Santos Schmidt ${ }^{2}$
}

Resumo: O presente estudo centrou-se no levantamento e análise da produção de pesquisa em educação ambiental (EA) nos três principais eventos científicos nacionais que incluem a EA entre seus grupos de trabalhos ou temáticas destacadas (ANPED, ANPPAS e EPEA) no período de 2001 a 2006. Os resultados apontam um perfil preliminar do especialista que está sendo legitimado como produtor de conhecimento em EA e as temáticas privilegiadas desses estudos. Destaca-se entre os pesquisadores autores dos trabalhos apresentados a predominância de doutores e doutorandos sobre mestres e mestrandos; do gênero feminino sobre o masculino; da vinculação às instituições públicas de ensino superior sobre as IES privadas; da proveniência das regiões Sudeste e Sul sobre as outras regiões do país. Os temas variaram para cada evento, mas a preocupação com a EA nos espaços formais de ensino e com a formação de professores foi uma constante.

Palavras-chave: Produção científica em EA, Perfil do pesquisador, Temas de pesquisa em EA.

Abstract: The present study focuses on the survey and analysis of the production of environment education (EE) research in the three main national scientific events that include EE in their working groups or featured themes (ANPED, ANPPAS and EPEA) in the period between 2001 and 2006. The results show a preliminary profile of the specialists who have been legitimated as knowledge producers in EE and the favoured themes of these studies. Among the authors of the works presented, there is a noticeable predominance of doctors over masters; of females over males; of public institutions of superior education over private ones; of the Southeast and South regions over the other three of Brazil. The subjects have varied from one event to another, but there was a constant concern with EE in the formal spaces of education and with teacher education.

Keywords: Scientific research on EE, Researcher's profile, Topics of research on EE.

\footnotetext{
1 Professora da Faculdade de Educação e do Programa de Pós-Graduação em Educação da PUCRS.E-mail:icmcarvalho@uol.com.br.

2 Graduada em Biologia pela ULBRA.
} 


\section{Introdução e justificativa}

Nesta pesquisa, pretendemos analisar a produção de pesquisa em educação ambiental como um dos aspectos da formação dessa esfera educativa do campo ambiental. Nosso ponto de partida é que a questão ambiental agencia um universo de significados delimitando um espaço de relações sociais que pode ser nomeado como campo ambiental. Esse processo de formação de um campo de relações sociais ${ }^{3} \mathrm{em}$ torno da questão ambiental no Brasil inclui a constituição de uma esfera educativa que se estrutura como parte do campo na condição de uma educação ambiental. Como tal, essa esfera de práticas educacionais reivindica a legitimação de um conhecimento válido, bem como de um novo profissional, o educador ambiental.

O campo ambiental, ao circunscrever certo conjunto de relações sociais, sentidos e experiências, configura um universo social particular que produz um conjunto de crenças, valores, uma ética, naturalizando certos modos de ver e se comportar que põem em ação as regras do jogo do campo. A crença que estrutura o campo ambiental pode ser relacionada ao reconhecimento da natureza e do ambiente como um Bem em si, para além de suas finalidades utilitárias. Esse Bem, valorizado pela educação, se oferece como um ideal para os processos de formação identitária. Dessa forma, valores, atitudes e práticas ecologicamente orientadas constituem a cumplicidade ontológica da qual fala Bourdieu (2004) e que faz com que os indivíduos e grupos sociais "entrem no jogo", incorporando a preocupação e o cuidado com o meio ambiente e a natureza como um parâmetro ético. As estratégias, posições e lutas que compõem esse campo podem ser reconstruídas e tematizadas nos processos de formação e legitimação dos "profissionais ambientais". Estes participam ao mesmo tempo em que constituem, dinamicamente, um campo social particular, e como tais estão sujeitos às regras de funcionamento desse campo.

Enquanto um espaço estruturado e estruturante, o campo ambiental inclui uma série de práticas e políticas pedagógicas, religiosas e

\footnotetext{
3 A noção de campo de relações sociais vem da sociologia da prática de Pierre Bourdieu e sua teoria dos campos sociais. Para uma apresentação do conceito, ver especialmente Bourdieu (2004).
} 
culturais, que se organizam de forma mais ou menos instituídas, seja no âmbito do poder público, seja na esfera da organização coletiva dos grupos, associações ou movimentos da sociedade civil; reúne e forma um corpo de militantes, profissionais e especialistas; formula conceitos e adquire visibilidade através de um circuito de publicações, eventos, documentos e posições sobre os temas ambientais. Ao tomar o campo ambiental como referência, podem-se compreender as motivações, os argumentos, valores, ou seja, aquilo que constitui a crença específica que sustenta um campo.

Tendo como preocupação de fundo esse processo mais amplo, a presente pesquisa se deteve num aspecto particular da formação do campo ambiental, notadamente em sua esfera pedagógica. Buscou focar parte do processo de produção e validação de um conhecimento legítimo em educação ambiental, bem como do reconhecimento de seus especialistas, os educadores ambientais. Essa dimensão particular da formação do campo passa pelo reconhecimento da educação ambiental nos espaços já instituídos e reconhecidos da pesquisa e produção de conhecimento em educação no Brasil. Podemos observar o caráter recente dessa entrada da educação ambiental no chamado circuito de alto nível da pesquisa em educação, tendo seu ingresso aceito em espaços da pesquisa e da PósGraduação em educação no Brasil (NOVICKI, 2003; LOUREIRO, 2006; SAITO, 2006; LORENZETTI; DELIZOICOV, 2007; LORENZETTI, 2008) 4 .

Nesse sentido, torna-se relevante identificar o processo de legitimação da educação ambiental observando sua entrada na Associação Nacional de Pesquisa e Pós-Graduação em Educação - ANPED, na Associação Nacional de Pesquisa e Pós-Graduação Ambiente e Sociedade - ANPPAS e no Encontro de Pesquisa em Educação Ambiental - EPEA.

\footnotetext{
${ }^{4}$ Para uma excelente análise global desse processo de consolidação da pesquisa em EA no âmbito da Pós-Graduação em ciências humanas nos últimos 30 anos no Brasil, ver os trabalhos de Lorenzetti, entre os quais destacamos seu artigo sobre a produção acadêmica brasileira em EA, de 2007, e sua tese de doutorado, de 2008.
} 


\section{Objetivos}

Objetivo Geral: analisar a instituição da EA como área de pesquisa e produção de conhecimento através da produção científica congênere apresentada em espaços representativos da pesquisa em nível de graduação e pós-graduação em âmbito nacional.

Objetivos específicos:

- Contribuir para a compreensão do perfil dos trabalhos de pesquisa em EA

- Contribuir para a compreensão do perfil dos pesquisadores em EA

- Oferecer elementos para uma caracterização da produção da pesquisa científica em Educação Ambiental no período e nos eventos pesquisados.

\section{Metodologia}

Foram selecionados como representativos da produção de pesquisa em EA em âmbito nacional os seguintes eventos acadêmicos: Associação Nacional de Pós-Graduação e Pesquisa Ambiente e Sociedade - ANPPAS, que desde sua formação em 2002 instituiu um Grupo de Trabalho voltado para temas da educação e meio ambiente, denominado GT Sociedade, Ambiente e Educação; a Associação Nacional de PósGraduação e Pesquisa em Educação - ANPED, a mais importante Associação Nacional de Pesquisa em Educação, que nos últimos anos instituiu um Grupo de Estudos (GE) e posteriormente, em 2004, aprovou o GT de EA; e o Encontros de Pesquisa em Educação Ambiental EPEA, evento de caráter interinstitucional, envolvendo a UNESP, USP e UFSCar, focalizado exclusivamente na pesquisa em EA e cuja primeira edição ocorreu em Rio Claro, SP, em 2001. Embora este evento não tenha nascido com o desenho de um encontro nacional, desde sua primeira edição teve uma resposta surpreendente e de maior abrangência do que previsto. Foi o primeiro evento de pesquisa em EA com essa magnitude e sua repercussão se manteve nas edições subseqüentes, vindo a constituir-se em um espaço destacado, voltado exclusivamente para a pesquisa em EA, 
de abrangência nacional. Por seu pioneirismo e alcance, consideramos que o EPEA é um espaço representativo da pesquisa em educação ambiental em âmbito nacional e o incluímos entre os eventos selecionados na pesquisa.

Com base nos anais dos eventos descritos, foi feito um levantamento dos trabalhos apresentados nas sessões de trabalho de todos os anos em que esses eventos ocorreram no período de 2001 a 2006. A periodicidade dos eventos variou: o EPEA e a ANPPAS são eventos bianuais e a ANPED é um evento anual. Em todos eles, os trabalhos apresentados passam por processo de avaliação e são legitimados pelas instituições promotoras do evento ${ }^{5}$, bem como atendem as regras e condições mais gerais dos eventos acadêmicos, uma vez que buscam financiamento junto às agências de fomento à pesquisa, como CAPES e CNPq.

Os trabalhos apresentados nos eventos foram levantados visando identificar o perfil do autor principal segundo o gênero, titulação, vínculo com Instituição de Ensino Superior (IES) e região do Brasil da IES. Também classificamos os trabalhos segundo seu interesse temático com base nos resumos e palavras-chave. Para o tratamento da grande variedade de assuntos específicos abordados nos trabalhos apresentados, agregamos esses interesses em categorias temáticas que permitissem uma visão mais global dos mesmos.

\section{Levantamento e análise dos dados}

\subsection{Associação de Pesquisa e Pós-Graduação em Educação - ANPED}

A ANPED é a associação científica mais antiga e prestigiada em educação no Brasil. Desde 1976, congrega associados em âmbito nacional. Seu objetivo é a consolidação do ensino de pós-graduação e da pesquisa

\footnotetext{
5 A ANPED e o EPEA recorrem em todas as suas edições a comitês científicos externos para a avaliação dos trabalhos. A ANPPAS destina essa atribuição aos coordenadores dos GTs.
} 
em Educação no Brasil. Atualmente, as reuniões da ANPED são consideradas eventos "Qualis Internacional A" pela CAPES.

Ao longo dos anos, tem se projetado como um importante fórum de debates das questões científicas e políticas da área, tornando-se referência para o acompanhamento da produção brasileira no campo educacional. Estrutura-se em dois âmbitos: os Programas de PósGraduação em Educação stricto sensu, que são representados no Fórum de Coordenadores dos Programas de Pós-Graduação em Educação EDUFORUM, e os Grupos de Trabalho - GTs. Estes últimos congregam pesquisadores interessados em áreas de conhecimento especializado em educação. Para serem constituídos, os GTs precisam ter funcionado durante dois anos no formato de Grupos de Estudo (GEs), com aprovação prévia da Assembléia Geral.

A entrada da Educação Ambiental como GT na ANPED é recente (data de 2005), tendo passado pelo processo preliminar de ser um GE desde 2003. Por essa razão, para efeito desta pesquisa, consideramos tanto os anos de existência do Grupo de Estudo (GE) como sua posterior transformação em Grupo de Trabalho (GT) pela Assembléia Geral da ANPED em 20046.

Gráfico 1. Trabalhos apresentados no GT de EA da ANPED de 2003 a 2006 segundo a titulação e o gênero dos/as autores/as.

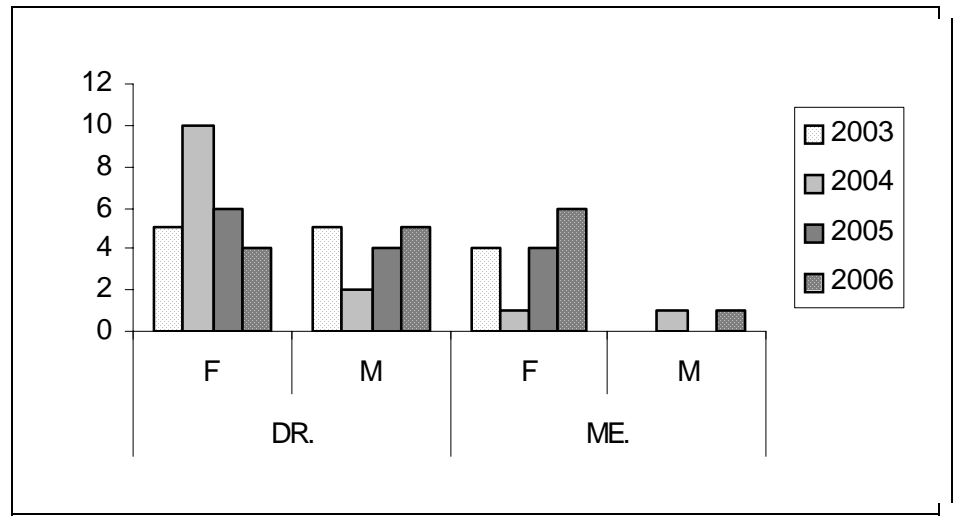

${ }^{6}$ Para uma análise do primeiro ano do GT de EA da ANPED, ver Loureiro (2006). 
Considerando o total de trabalhos, há uma predominância de doutores e doutorando/as (70,7\%) sobre mestres e mestrando/as (29,3\%), bem como do gênero feminino (69\%) sobre o masculino (31\%). As doutoras e doutorandas predominam entre o grupo de autores de trabalhos na ANPED, representando $43 \%$ dos trabalhos.

Gráfico 2. Trabalbos apresentados no GT de EA da ANPED de 2003 a 2006 segundo a natureza da IES.

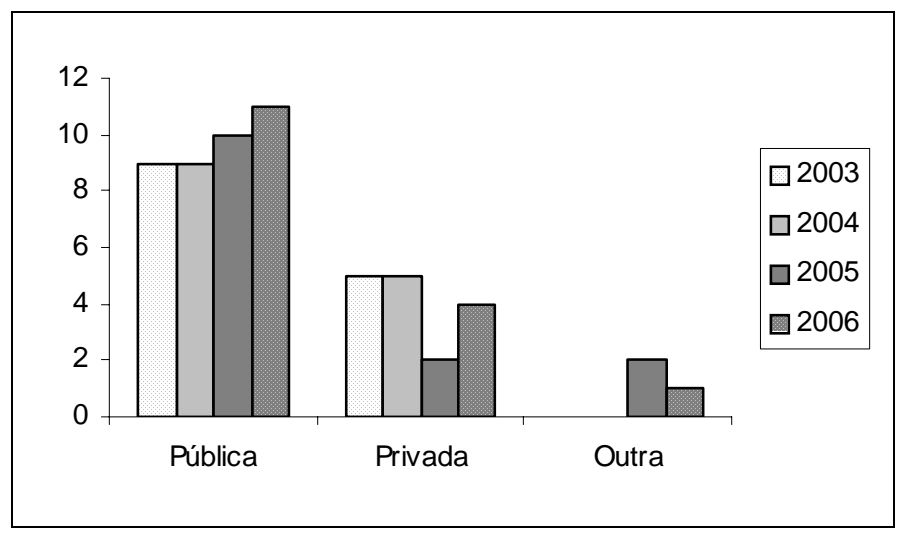

As IES são a grande maioria entre as instituições de ensino e, nesse universo, predominam as IES públicas (71\%) sobre as privadas (29\%). As outras instituições de ensino dizem respeito a Escolas Técnicas Federais (CEFETs) e Secretarias de Educação, ambos os tipos pertencentes à rede pública. 
Gráfico 3. Procedência dos trabalhos apresentados no GT de EA da ANPED de 2003 a 2006 segundo as regiões do Brasil.

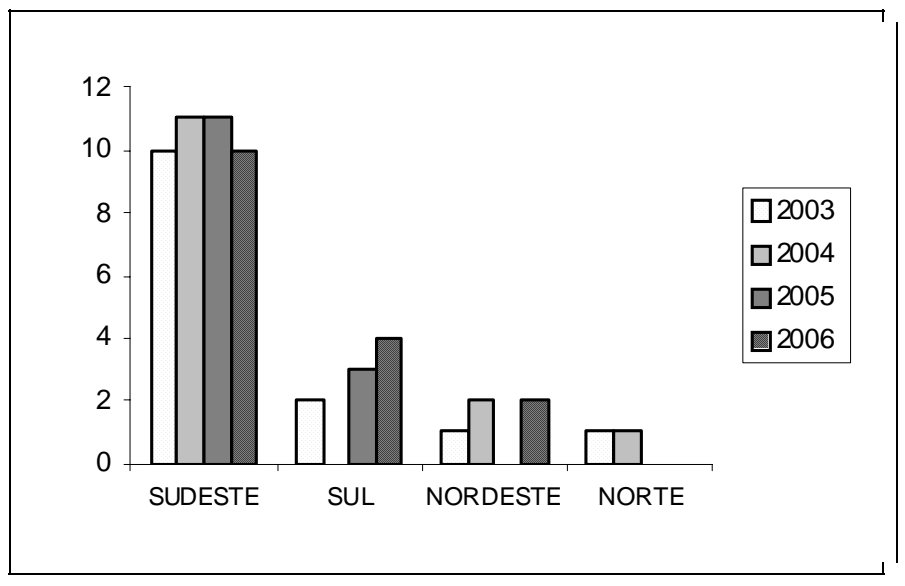

Quanto às regiões das instituições de proveniência dos trabalhos, há predomínio das regiões Sudeste $(72,4 \%)$ e Sul $(15,5 \%)$, com pequena representatividade das regiões Nordeste e Norte $(8,6 \%$ e 3,5\%, respectivamente) e ausência da região Centro-Oeste no período analisado.

Tabela 1. Trabalhos apresentados no GT de EA da ANPED de 2003 a 2006 segundo as categorias temáticas.

\begin{tabular}{|l|cccc|c|}
\hline TEMA & 2003 & 2004 & 2005 & 2006 & Total \\
\hline Fundamentos da EA & 5 & 3 & 2 & 5 & 15 \\
EA no ensino formal & 2 & 3 & 2 & 5 & 12 \\
EA popular & 3 & 2 & 1 & 1 & 7 \\
Os sentidos da EA & 1 & 3 & 1 & 0 & 5 \\
EA no debate ambiental & 0 & 2 & 2 & 1 & 5 \\
EA na cultura & 1 & 0 & 1 & 2 & 4 \\
EA na gestão ambiental & 1 & 1 & 0 & 1 & 3 \\
EA na formação de professores & 1 & 0 & 3 & 0 & 4 \\
EA e subjetividade/identidade & 0 & 0 & 1 & 1 & 2 \\
\hline Total & 14 & 14 & 14 & 16 & 58 \\
\hline
\end{tabular}


Considerando as temáticas abordadas com mais freqüência no GE/GT de EA da ANPED, destacam-se os trabalhos relacionados à discussão de bases teóricas e metodológicas de propostas, práticas e concepções de EA. Esses trabalhos tiveram em comum a aplicação à EA de certas tradições teóricas, conceitos e autores específicos, buscando o aprofundamento da compreensão e/ou construção de fundamentos epistemológicos da EA. Ainda foram incluídos nessa categoria trabalhos que investigaram a produção em EA destacando orientações teóricas e metodológicas. Em seguida, aparecem as temáticas relacionadas ao ensino formal, as quais incluíram trabalhos sobre atividades e/ou projetos de EA no sistema formal de ensino nos seus diferentes níveis (fundamental, médio e superior), sobre EA no espaço escolar, EA e suas relações com o currículo escolar, EA e a discussão da interdisciplinaridade nas praticas escolares e EA nos livros e materiais pedagógicos. Num recorte analítico mais abrangente, se agregarmos à categoria $E A$ no ensino formal (12) a categoria $E A$ na formação de professores (4), podemos afirmar que a relação com o ensino formal esteve presente em pelo menos 16 trabalhos entre os 58 , sendo a preocupação temática mais expressiva. Considerando entre o conjunto das outras temáticas aquelas que têm em comum o âmbito não formal da realização da $\mathrm{EA}$, seria possível agregar: $E A$ popular (7), EA e gestão ambiental (3) e EA na cultura (4), e com isso poderíamos considerar que a EA não formal foi objeto de preocupação de pelo menos 14 trabalhos, ficando logo abaixo da EA relacionada aos espaços formais do ensino. A categoria temática denominada os sentidos da $E A$ (5) reuniu trabalhos cuja ênfase esteve em pesquisar as representações, percepções e os sentidos conferidos ao meio ambiente visando pensar e avaliar práticas de EA por parte de grupos específicos, como professores de ciências, professores de geografia, grupos ecologistas, comunidades tradicionais, grupos religiosos etc. Esses trabalhos poderiam ter sido categorizados em outros eixos (ora em EA popular, ora em formação de professores, por exemplo), mas optou-se por destacá-los nesse porque nos chama a atenção a recorrência dessa abordagem entre trabalhos apresentados em congressos de EA. A categoria EA no debate ambiental indica as discussões feitas nos trabalhos apresentados a respeito das grandes problemáticas do campo ambiental, tais como desenvolvimento sustentável, conflitos ambientais, 
direito ambiental, aquecimento global, turismo ecológico, entre outras. Esses trabalhos trazem questões conceituais e aplicadas, mas não necessariamente visando a fundamentação teórico-metodológica da EA. O que eles parecem indicar é o estado do diálogo da EA com o campo ambiental mais amplo e suas problemáticas. Finalmente, quisemos verificar os trabalhos que tiveram uma preocupação com o tema formação de subjetividade/identidade em $E A$ mensurando a interface possível da pesquisa em EA com a psicologia social, o que se mostrou bastante inexpressivo, com apenas 2 trabalhos.

\subsection{Associação Nacional de Pós-Graduação e Pesquisa em Ambiente e Sociedade - ANPPAS/ Grupo de Trabalho (GT) Sociedade, Ambiente e Educação}

A Associação Nacional de Pós-Graduação e Pesquisa em Ambiente e Sociedade - ANPPAS é uma associação recente (surgiu em 2002) e representa um tipo novo de associação científica, que já nasce interdisciplinar e inclui desde o início a educação ambiental em sua agenda temática. Trata-se de uma iniciativa de um conjunto de Programas de PósGraduação (PPGs) interdisciplinares para dar conta de uma lacuna de representação na comunidade acadêmica dos Programas vinculados aos estudos ambientais dentro das associações científicas disciplinares já existentes. Congrega PPGs, Centros e Núcleos de pesquisa. ${ }^{7}$

\footnotetext{
${ }^{7}$ Segundo o site da ANNPAS, consultado em 2008, a Associação é formada por instituições como: o Núcleo de Estudos e Pesquisas Ambientais da Universidade Estadual de Campinas - NEPAM/UNICAMP; o Núcleo de Altos Estudos Amazônicos, da Universidade Federal do Pará - NAEA/UFPA; o Centro de Desenvolvimento Sustentável, da Universidade de Brasília - CDS/UnB; o Programa de Pós-Graduação em Psicossociologia de Comunidades e Ecologia Social - EICOS/UFRJ; o Programa de PósGraduação Interunidades em Ecologia Aplicada (PPGI-EA-USP) (ESALQ/CENA/USP); o Programa de Mestrado em Gestão Integrada em Saúde do Trabalho e Meio Ambiente - SENAC; o Programa de Pós-Graduação de Ciências Sociais em Desenvolvimento, Agricultura e Sociedade - CPD, da Universidade Federal Rural do Rio de Janeiro - UFRRJ; o Programa de Pós-Graduação Interdisciplinar em Ciências Humanas, da Universidade Federal de Santa Catarina; o Doutorado em Meio Ambiente e Desenvolvimento, da Universidade Federal do Paraná; o Programa de Mestrado em Ciência Ambiental, da Universidade de São Paulo - PROCAM/USP; e vários dos Programas Regionais de Pós-Graduação em Desenvolvimento e Meio Ambiente - os chamados PRODEMAS.
} 
A ANPPAS busca articular programas e instituições de pesquisa e formação em nível de Pós-Graduação cujas áreas de concentração estejam voltadas para as relações Ambiente e Sociedade. Na primeira reunião da ANPPAS, foi proposto um conjunto de Grupos de Trabalhos em que já estava previsto um GT voltado especificamente para a educação ambiental, o qual se chamou "sociedade da informação, educação e meio ambiente". $\mathrm{Na}$ segunda reunião da ANPPAS, realizada em 2004, o grupo foi renomeado como "Sociedade, Ambiente e Educação". Para efeito desta pesquisa, usaremos sempre esse segundo nome do GT, que é o que se mantém até hoje. Os encontros da ANPPAS são bianuais, portanto, no contexto desta pesquisa são consideradas as edições de 2002, 2004 e 2006.

Gráfico 4. Trabalhos apresentados no GT Sociedade, Ambiente e Educação da ANPPAS de 2002 a 2006 segundo a titulação e o gênero dos/as autores/as.

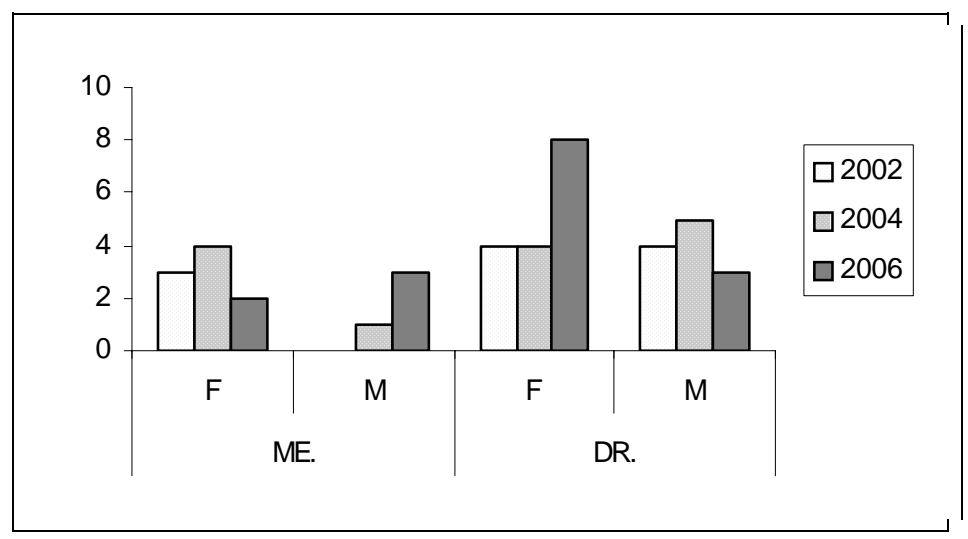

Considerando os três encontros bianuais da ANPPAS, a presença mais significativa é de doutores e doutorandos (68,3\%) sobre mestres e mestrandos (31,7\%), bem como de mulheres (61\%) sobre homens $(39 \%)$, indicando a predominância de autoras doutoras e doutorandas entre os trabalhos apresentados $(39 \%)$. 
Gráfico 5. Trabalhos apresentados no GT Sociedade, Ambiente e Educação da ANPPAS de 2002 a 2006 segundo o caráter público ou privado da IES.

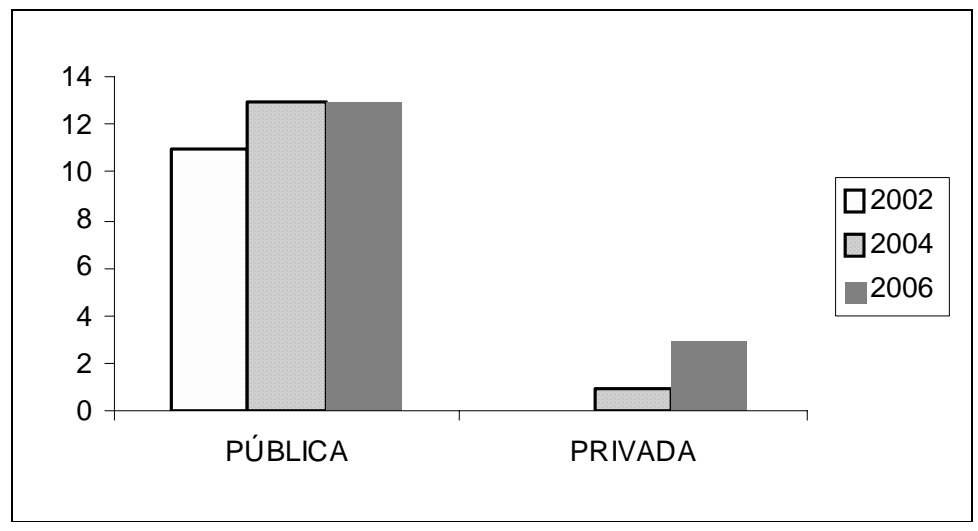

Há uma expressiva predominância do vínculo dos autores dos trabalhos com instituições públicas de ensino superior. Dos 41 trabalhos apresentados nas três edições estudadas da ANPPAS, 37 foram oriundos de IES públicas, ou seja, 90,3\% do total.

Gráfico 6. Procedência dos trabalhos apresentados no GT Sociedade, Ambiente e Educação da ANPPAS de 2002 a 2006 segundo as regiões do Brasil.

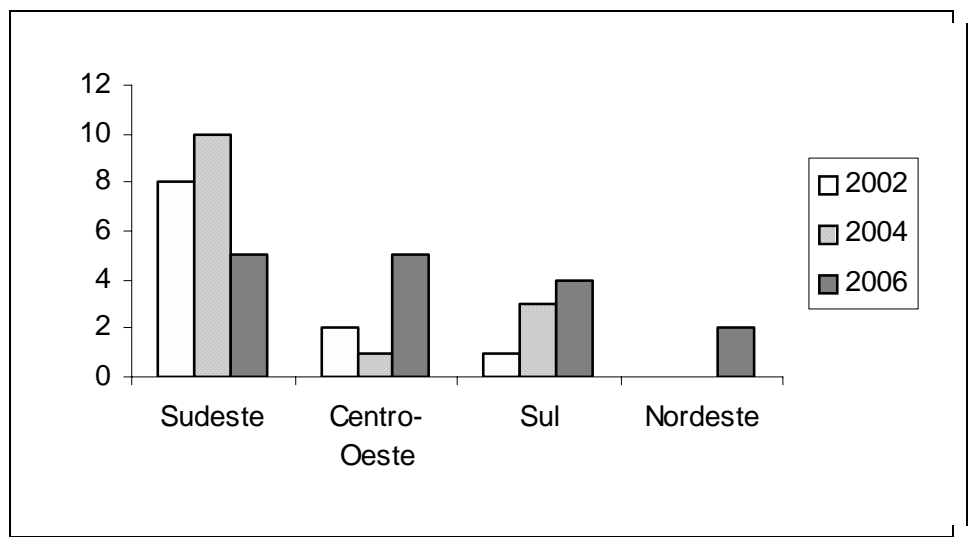


A região Sudeste é a mais representada nas edições da ANPPAS avaliadas, com uma fatia de 56,1\%. Destaca-se também a ausência de trabalhos provenientes da região Norte no conjunto dos encontros. Esse dado mostra, por um lado, a ainda pequena representação nacional da ANPPAS - em parte, talvez, por ser uma Associação recente e que nasceu pela iniciativa de PPGs do Sul e Sudeste, cujas primeiras reuniões foram em Campinas -, mas também pode refletir a menor presença de PPGs interdisciplinares na região Norte.

Tabela 2. Trabalhos apresentados no GT Sociedade, Ambiente e Educação da ANPPAS de 2002 a 2006 segundo as categorias temáticas.

\begin{tabular}{|l|c|c|c|c|}
\hline TEMA & $\mathbf{2 0 0 2}$ & $\mathbf{2 0 0 4}$ & $\mathbf{2 0 0 6}$ & Total \\
\hline EA popular & 4 & 3 & 5 & 12 \\
\hline EA na formação de professores & 2 & 4 & 1 & 7 \\
\hline EA no ensino formal & 2 & 1 & 3 & 6 \\
\hline Fundamentos da EA & 0 & 4 & 2 & 6 \\
\hline EA no debate ambiental & 2 & 1 & 2 & 5 \\
\hline Os sentidos da EA & 0 & 1 & 1 & 2 \\
\hline EA na gestão ambiental & 1 & 0 & 0 & 1 \\
\hline EA e subjetividade/identidade & 0 & 0 & 1 & 1 \\
\hline EA na cultura & 0 & 0 & 1 & 1 \\
\hline Total & 11 & 14 & 16 & 41 \\
\hline
\end{tabular}

O tema que sozinho agregou maior número de trabalhos foi a $E A$ popular (12), em geral relacionada a intervenções comunitárias em espaços não formais. A EA em espaços não formais ainda poderia abranger temas como $E A$ na gestão ambiental e $E A$ na cultura, chegando a 14 trabalhos no total. Por outro lado, se agregarmos os temas que envolvem as questões da EA no ensino formal (6) e EA na formação de professores (7), teremos 13 trabalhos cuja preocupação esteve relacionada à EA formal. Foram esses os dois grandes agrupamentos temáticos. A discussão de tipo teórica e epistemológica ficou com 6 trabalhos, seguida pela EA no debate ambiental (5). As outras temáticas se mostraram claramente minoritárias, como as relativas à $E A$ e identidade/subjetividade (1), EA na gestão ambiental e (1) EA na 
cultura (1). Também chama a atenção que as categorias $E A$ popular, EA na formação de professores e $E A$ no ensino formal são as únicas que aparecem em todos os encontros, indicando certa regularidade e estabilidade dessas preocupações nos 6 anos pesquisados.

\subsection{Encontro de Pesquisa em Educação Ambiental - EPEA}

O EPEA foi idealizado por três universidades públicas de São Paulo: UFSCar, UNESP/Rio Claro e USP/Ribeirão Preto, envolvendo a participação do Grupo de Pesquisa em Ensino de Ciências do Laboratório Interdisciplinar de Formação do Educador (LAIFE), da Faculdade de Filosofia, Ciências e Letras de Ribeirão Preto/USP; do Programa de PósGraduação em Educação da UNESP/Rio Claro; e dos Programas de PósGraduação em Ecologia e Recursos Naturais e em Educação da UFSCar.

O I EPEA foi realizado em $2001 \mathrm{em}$ Rio Claro/SP, o II EPEA, em 2003 em São Carlos/SP, o III EPEA, em 2005 em Ribeirão Preto/SP e o IV EPEA aconteceu em 2007 na UNESP de Rio Claro. Em todas as suas edições, manteve como objetivos: identificar e analisar as tendências e perspectivas da produção científica sobre Educação Ambiental (EA); criar espaços de apresentação e debate de relatos de pesquisa em EA; dar continuidade ao levantamento do estado da arte da pesquisa em Educação Ambiental no país e suas perspectivas, iniciado nas edições anteriores do EPEA; e identificar possibilidades teórico-metodológicas significativas para as pesquisas relacionadas com a Educação Ambiental, bem como as prioridades que possam orientar os esforços e investimentos na área.

Como já justificamos anteriormente, embora o EPEA seja um espaço diferente das Associações de Pesquisa Nacionais, foi considerado relevante neste levantamento pelo fato de ter inaugurado um espaço acadêmico de debate e apresentação da produção de pesquisa em EA, com significativa aceitação pela comunidade de pesquisadores, com abrangência nacional e com o apoio das agências nacionais de fomento. Nessa condição, o EPEA vem se consolidando como um evento de referência na área da EA, conforme apontam vários estudos (AVANZI; SILVA, 2004; CAVALARI; SANTANA; CARVALHO, 2006; FREITAS; OLIVEIRA, 2006; KAWASAKI; MATOS; MOTOKANE, 2006). 
Diferentemente dos outros eventos, que são exclusivamente voltados à Pós-Graduação, o EPEA destina-se ao nível universitário, abrangendo a graduação e a pós-graduação estrito e lato senso.

Gráfico 7. Trabalhos apresentados no EPEA de 2001 a 2005 segundo a titulação e o gênero dos autores/as.

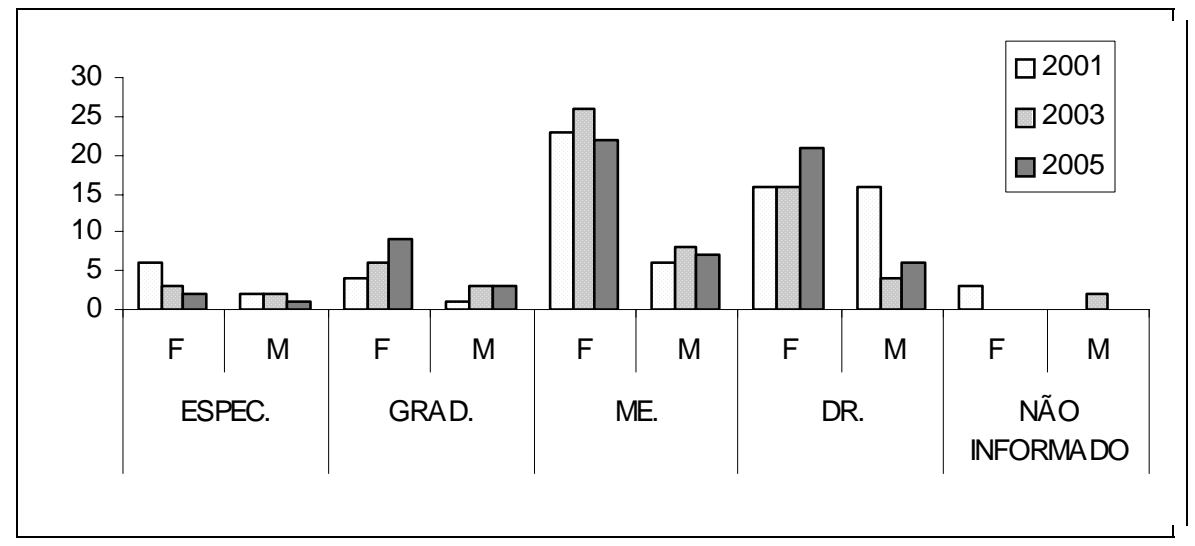

Observa-se a predominância do gênero feminino $(72 \%)$ entre os participantes em todos os níveis de titulação, da graduação ao doutorado, o que reafirma a tendência já verificada nos outros eventos analisados (ANPED e ANPPAS),. Com relação à titulação, observou-se uma maioria de mestres e mestrandos/as (42,2\%) sobre outros níveis de titulação8.

\footnotetext{
${ }^{8}$ No cômputo total dos trabalhos apresentados, não consideramos quando um mesmo autor apresentou mais de um trabalho. Também foi excluído 1 trabalho de instituição estrangeira apresentado no I EPEA (2001). Essa exclusão se justifica neste levantamento porque o foco é a produção em pesquisa no Brasil.
} 
Gráfico 8. Procedência dos trabalhos apresentados no EPEA de 2001 a 2005 quanto à natureza da IES.

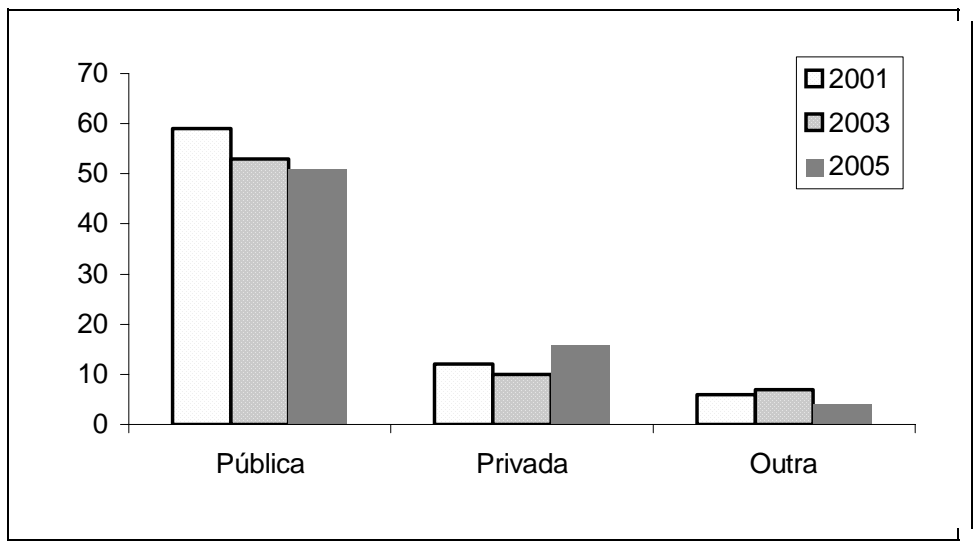

Os trabalhos apresentados provêm em sua grande maioria das IES $(92 \%)$. Entre estas, predominam as IES públicas sobre as privadas na produção dos trabalhos de pesquisa apresentados - 74,8\% e 17,4\%, respectivamente. Esse cenário se mantém nas três realizações do EPEA e indica que a pesquisa em EA acompanha o quadro da pesquisa acadêmica no Brasil nas ciências humanas, produzida em maior escala nas universidades públicas ${ }^{9}$. No EPEA, diferentemente da ANPED e ANPPAS, há uma presença um pouco mais visível de outros tipos de instituição de pesquisa, como fundações, ONGs e institutos, que não aparecem nos outros eventos devido à orientação de congregar exclusivamente instituições acadêmicas para a Pós-Graduação .

\footnotetext{
${ }^{9}$ É interessante observar, contudo, o estudo de Kawasaki, Matos e Motokane de 2006, que levantou a instituição da formação inicial dos pesquisadores do I EPEA e constatou que, embora a maioria destes venha de IES públicas, é significativa a procedência de IES privadas, que alcançou $32 \%$ contra $22 \%$ de IES federais e $44 \%$ de IES estaduais.
} 
Gráfico 9. Procedência dos trabalhos apresentados no EPEA de 2001 a 2005 segundo as regiões do Brasil.

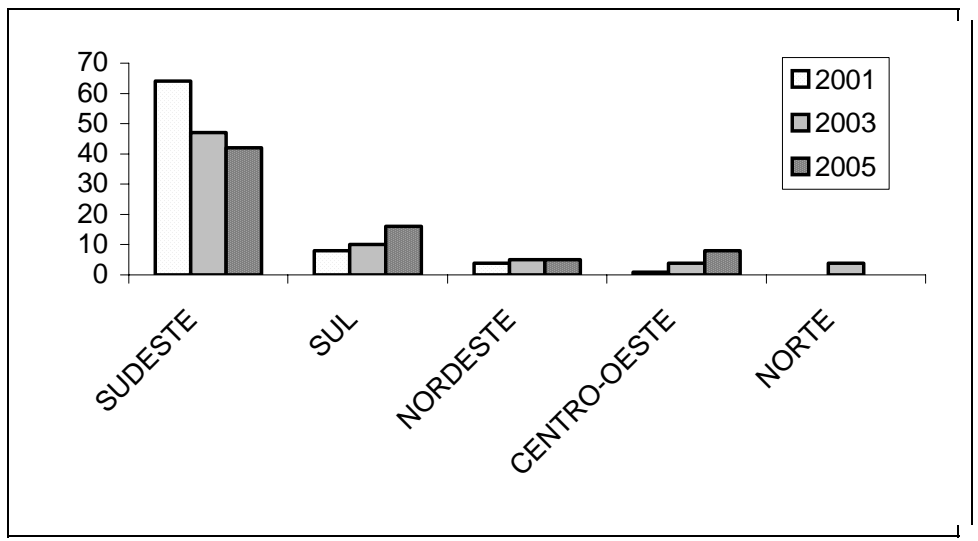

A região Sudeste participa com 70,2\% dos trabalhos apresentados, sendo, portanto, a região com maior participação no EPEA. Em segundo lugar, está a região Sul, com 15,6\% do total, seguida pelas regiões Nordeste e Centro-Oeste, com $6,4 \%$ e $6 \%$ dos trabalhos apresentados, respectivamente. Em quarto lugar, está a região Norte, com apenas 1,8\% dos trabalhos. Esse quadro mostra o predomínio do eixo Sudeste-Sul, regiões que, agregadas, somam 85,8\% dos trabalhos, ao passo que as outras três regiões do Brasil somam juntas menos de 15\% dos trabalhos. Apesar de a predominância do eixo Sudeste-Sul se repetir nos eventos ANPED, ANPPAS e EPEA, é apenas neste último que, mesmo com uma presença minoritária, aparecem trabalhos provenientes de todas as regiões.

Tabela 3. Trabalhos apresentados no EPEA de 2001 a 2005 segundo as categorias temáticas.

\begin{tabular}{|l|c|c|c|c|}
\hline TEMA & $\mathbf{2 0 0 1}$ & $\mathbf{2 0 0 3}$ & $\mathbf{2 0 0 5}$ & Total \\
\hline Os sentidos da EA & 12 & 18 & 10 & 40 \\
\hline EA na gestão ambiental & 15 & 12 & 11 & 38 \\
\hline EA no ensino formal & 17 & 6 & 11 & 34 \\
\hline Fundamentos da EA & 7 & 6 & 14 & 27 \\
\hline EA na formação de professores & 10 & 5 & 7 & 22 \\
\hline
\end{tabular}




\begin{tabular}{|l|c|c|c|c|}
\hline EA popular & 5 & 9 & 7 & 21 \\
\hline EA na cultura & 6 & 4 & 7 & 17 \\
\hline EA no debate ambiental & 5 & 8 & 4 & 17 \\
\hline EA e subjetividade/identidade & 0 & 2 & 2 & 4 \\
\hline Outros & 1 & 2 & 0 & 3 \\
\hline Total & 78 & 72 & 73 & 223 \\
\hline
\end{tabular}

Entre os temas abordados, observamos uma expressiva concentração de trabalhos voltados para a análise do que nomeamos os sentidos da EA (40), mostrando que a preocupação com a compreensão de noções como ambiente, natureza e mesmo da própria EA por parte de grupos específicos (como professores, estudantes, crianças etc.) parece bastante significativa no conjunto de pesquisas do universo do EPEA. Se agregarmos as temáticas relacionadas à $E A$ no ensino formal (34) e $E A$ na formação de professores (22), teremos 56 trabalhos. A gestão ambiental aparece como a segunda maior preocupação quando analisada isoladamente, com 38 trabalhos. Foram incluídos os trabalhos voltados para a EA realizada em áreas de gestão ambiental, como as UCs, e de análise de programas de políticas públicas de EA, ou a EA em programas ambientais, como manejo de bacias hidrográficas e programas de despoluição. O tema Fundamentos da $E A$ é o quarto em evidência, com 27 trabalhos. A EA popular não se destacou no conjunto dos trabalhos, ficando em sétimo lugar, com 21 trabalhos. Os temas menos recorrentes foram a $E A$ na cultura e a $E A$ no debate ambiental, ambos com 17 trabalhos, e, seguindo a tendência dos outros eventos, a categoria EA e a temática identidade/subjetividade foi a mais inexpressiva.

\section{Interpretação dos dados considerando os trabalhos apresentados na ANPED, ANPPAS e EPEA}

A predominância do feminino em todos os niveis de titulação

Quanto à titulação, tanto na ANPED quanto na ANPPAS, eventos voltados para a produção em nível de Pós-Graduação, há uma predominância de doutores e doutorandos/as sobre mestres e mestrandos/as. Quanto à relação entre titulação e gênero, observa-se em 
ambos os eventos a predominância do gênero feminino. Na ANPED, essa correlação se mostra muito significativa com o predomínio de mulheres tanto na categoria doutores/as quanto na categoria mestres. Já na ANPPAS, a dominância do gênero feminino permanece, embora a discrepância seja menos acentuada na categoria de maior titulação doutores/as e doutorandos/as.

No EPEA, evento que inclui outros níveis do ensino superior, a predominância do gênero feminino se mantém da graduação ao doutorado. Contudo, diferentemente dos outros eventos analisados, nos quais predominam doutores/as e doutorandos/as, no EPEA a titulação predominante foi a de mestres e mestrandos/as (42\%).

É interessante pensar sobre os possíveis significados dessa predominância do gênero feminino de pesquisadores em EA nos eventos investigados. Por um lado, teríamos de considerar que o universo que estamos pesquisando está fortemente ligado à educação, que tem sido historicamente um campo feminino. Esse dado não é novo e há estudos na educação que discutem a chamada feminização (WERLE, 2005; COSTA, 2006) das carreiras de educação tradicionalmente associadas ao trabalho feminino, ao cuidado e à menor remuneração. Devemos considerar ainda o perfil das relações de gênero na sociedade: embora de maneira geral as mulheres estejam avançando na ocupação de cargos no mercado de trabalho, essa ocupação se distribui de modo diferente segundo o gênero, e as mulheres aparecem mais relacionadas a atividades de educação e serviços sociais ${ }^{10}$. É inegável o avanço dos indicadores de escolarização das

10 A Pesquisa Nacional Por Amostra de Domicílios (PNAD) realizada em 2007 aponta que a maior participação das mulheres no mercado de trabalho tem se concentrado em quatro grandes categorias ocupacionais que, juntas, compreendem cerca de $70 \%$ da mão-de-obra feminina: serviços em geral (30,7\%); trabalho agrícola (15\%); serviços administrativos $(11,8 \%)$; e comércio $(11,8 \%)$. Para as mulheres ocupadas mais escolarizadas, com média de 12 anos de estudo ou mais, a inserção no mercado de trabalho é mais intensa nas atividades de educação, saúde e serviços sociais (44,5\%). No caso da população masculina mais qualificada, a inserção no mercado de trabalho é mais diversificada e em atividades melhor remuneradas, o que de certa forma explica parte da desigualdade entre homens e mulheres no que se refere ao rendimento. Observa-se que 23,6\% deles estão em outras atividades; $16,7 \%$, na indústria; $15,9 \%$, nos setores de educação, saúde e serviço social; 14,7\%, no comércio e reparação; e 13,3\%, na administração pública. 
mulheres, e sua participação no mercado de trabalho é uma tendência que se mantém crescente na ultima década ${ }^{11}$.

Nos dados que levantamos, parece significativo no campo da educação ambiental o avanço da escolarização das mulheres em nível de Pós-Graduação. Assim, podemos supor que as educadoras ambientais, acompanhando essa trajetória do que poderíamos chamar de um processo de empoderamento das mulheres no plano da escolarização e titulação de alto nível, têm conseguido ocupar cargos profissionais relativos à sua titulação, bem como disputar financiamentos e apoios institucionais de pesquisa com sucesso. Seria interessante verificar por meio de outras pesquisas se essa realidade se repete em outras áreas da educação e em que grau ou proporção isso acontece. De todo modo, considerando os indicadores sociais brasileiros e os dados de gênero evidenciados nesta pesquisa, teríamos razões para pensar que a desigualdade de gênero, uma herança que está na base de nossa formação social e histórica, parece estar sendo equalizada no que diz respeito ao universo da educação e pesquisa em EA, em continuidade com a tendência mais ampla de empoderamento das mulheres no âmbito da escolarização, da profissionalização e da inserção num mercado de trabalho qualificado.

\section{Predominância da procedência de trabalhos de IES públicas}

Quanto à procedência dos trabalhos segundo a natureza pública ou privada das IES, em todos os casos, há uma clara predominância das pesquisas em EA com origem nas IES públicas. Destacamos que foi na ANPED que se expressou, mesmo sendo minoritária, uma participação mais representativa de pesquisadores vindos de IES privadas. A relação entre pesquisa e universidade pública já é conhecida, pois, a despeito das dificuldades do setor público, a universidade pública mantém a liderança na pesquisa no Brasil, especialmente nas áreas das ciências humanas. Isso se deve principalmente ao regime de dedicação exclusiva do professor e às

\footnotetext{
11 Segundo o IBGE (2007), o aumento da qualificação feminina tem se intensificado nos últimos anos e tende a ser ainda maior. Em 1996, do conjunto das pessoas que freqüentavam estabelecimentos de ensino superior, a proporção de mulheres era de $55,3 \%$, passando para 57,5\% em 2006. Esses dados revelam que os homens estão perdendo espaço no processo de escolarização, pelo menos no que tange à taxa de escolarização superior.
} 
suas atribuições de pesquisa como política generalizada dessas instituições. As universidades privadas costumam ter um regime mais diversificado de trabalho, combinando professores de tempo integral com professores horistas, e muitas delas têm uma história recente nos cursos de PósGraduação, nos quais a pesquisa ganha centralidade entre as atividades-fim do professor.

\section{Predominância das regiões Sudeste e Sul}

Os trabalhos provenientes das regiões Sudeste e Sul predominaram nos três eventos acadêmicos analisados. No GT de EA da ANPED, em todo o período analisado a região Norte esteve ausente e a região Nordeste teve pequena representação ${ }^{12}$. Na ANPPAS, em todo o período analisado as regiões Norte e Nordeste estiveram ausentes e a região Centro-Oeste teve pequena representação. No EPEA, no período analisado, embora tenha havido a predominância das regiões Sudeste e Sul, não houve nenhuma região ausente, ou seja, as regiões Norte, Nordeste e Centro-Oeste também estiveram representadas, apesar do menor número de trabalhos. A única exceção foi a terceira edição do EPEA, em que não houve presença de nenhum trabalho vindo da região Norte.

Especialmente nos eventos ANPED e ANPPAS, que são encontros de associações nacionais, essa predominância das regiões Sudeste e Sul aponta a dificuldade de interiorização dessas iniciativas. Não podemos nos esquecer de que a realização desses eventos, no período pesquisado, aconteceu sempre na região Sudeste. Isso não deixa de revelar as desigualdades regionais no Brasil, já que a região Sudeste concentra a maioria da população brasileira e também a maior presença de mestres e

\footnotetext{
12 Como já analisou Loureiro (2006) para o GT de EA da ANPED, é visível a preponderância de trabalhos apresentados por pessoas oriundas do Sul e do Sudeste. Isso, provavelmente, não é uma exclusividade do GT de Educação Ambiental nem da ANPED; reflete a própria desigualdade regional que persiste no país nestes momentos de troca e publicização do conhecimento. Contudo, promover a reversão desse cenário não é fácil, pois, além da desigualdade no financiamento de projetos de pesquisa, o deslocamento para participar de eventos das regiões Norte e Nordeste para cidades do Sudeste como Indaiatuba, Poços de Caldas e Caxambu e a obtenção de apoio financeiro para isso não são tarefas das mais simples.
} 
doutores, bem como de Programas de Pós-Graduação ${ }^{13}$. Essa mesma tendência de a produção sobre EA estar concentrada na região Sudeste já foi observada por Novicki (2003) ao verificar que o crescimento da produção discente sobre EA tem destaque no Sudeste ${ }^{14}$. Tais dados nos fazem pensar na importância de políticas de estímulo ao equilíbrio regional e de interiorização do desenvolvimento da pesquisa em EA nas demais regiões do país.

\section{Eixos temáticos das pesquisas em EA}

Muitas são as possibilidades de recortar em categorias temáticas os trabalhos apresentados, como se pode observar na grande variedade de recortes já formulados nos vários artigos que já se dedicaram a algum tipo de sistematização temática ou mesmo de análise das concepções de EA nos trabalhos de pesquisa nos mesmos espaços analisados neste texto (RAMOS; GUERRA; GAZZOLA, 2005; CAVALARI; SANTANA; CARVALHO, 2006; KAWASAKI; MATOS; MOTOKANE, 2006; LOUREIRO, 2006; SATO, 2006) ${ }^{15}$.

${ }^{13}$ Em se tratando de educação ambiental, vale lembrar que o Sudeste é também a região brasileira onde se concentra a maior parte dos movimentos ambientalistas.

14 Segundo Novicki (2003), que pesquisou o banco de dados da ANPED nas décadas de 80 e 90 (1981 a 1998), houve um crescimento da produção discente em EA no Brasil de 0,99\% em 1996 para 1,07\% em 1998, ou seja, aumento de 34,7\%, sendo a região Sudeste a que melhor desempenho obteve $(61,3 \%)$. Nesse período, a região Norte não contou com nenhuma dissertação ou tese em EA.

15 Ramos, Guerra e Gazolla usaram as categorias formaşão docente, EA e curriculo, fundamentos epistemológicos, EA e comunidades, Inclusão social, Sustentabilidade e Práticas Pedagógicas para analisar os trabalhos apresentados no primeiro ano do GE da ANPED em 2003. Loureiro, ao analisar os trabalhos do GT de EA em 2006, verificou uma tendência para a vinculação da Educação Ambiental com o universo escolar e a presença de trabalhos que abordam questões relativas a opções metodológicas inseridas em determinadas tradições filosóficas bastante consolidadas nas ciências e na filosofia (como a hermenêutica e a dialética marxiana). $\mathrm{O}$ autor também destacou trabalhos com incursões mais ou menos diretas em autores pós-estruturalistas e pós-críticos, perspectivas teóricas recentes que estão sendo utilizadas de modo mais intenso em GTs como Currículo, Didática e Formação de Professores, com inserções medianas em GTs como Filosofia da Educação e Educação e Comunicação e estando praticamente ausentes em GTs como Trabalho e Educação, Políticas de Ensino Superior e Estado e Política Educacional, em função de suas histórias e objetos de pesquisa. Outros trabalhos são descritos como referentes a discussões conceituais com base em resultados de campo. 
Quanto aos eixos temáticos, verificamos que variaram em cada um dos eventos analisados. Retomamos as principais tendências de cada um dos eventos para propiciar uma visão geral das temáticas abordadas em cada um deles.

A despeito da pouca tradição dos trabalhos de EA de se voltarem para os referenciais teóricos, como destacado por Novicki (2003) e Ramos, Guerra e Gazzola (2005), podemos observar que essa preocupação tem sido especialmente destacada na ANPED. No GT de EA da ANPED, o interesse pelos aspectos teóricos e metodológicos aplicados à EA está presente em quase 50\% dos trabalhos. Considerando ainda que essa mesma preocupação ficou em quarto lugar entre os temas abordados tanto na ANPPAS quanto no EPEA, podemos dizer que entre os espaços da pesquisa em EA parece que a discussão teórica se concentra na ANPED. Considerando as temáticas agregadas, a $E A$ na educação formal é um pouco mais expressiva que as temáticas que se ocupam da EA em espaços não formais de educação relacionados, por exemplo, a EA em áreas naturais, comunidades e grupos sociais, bem como em atividades, produtos e expressões culturais.

$\mathrm{Na}$ ANPPAS, diferentemente da ANPED, a categoria temática Fundamentos da $E A$ aparece em quarto lugar, com 6 trabalhos, e a preocupação com a EA popular aparece em primeiro lugar, com 12 trabalhos. A preocupação com as intervenções da EA em espaços não formais agregou o bloco mais expressivo de trabalhos, seguido de perto pelos trabalhos voltados para a EA no ensino formal. Esses resultados apontam para um perfil diferente de preocupações, em que se destacam os trabalhos sobre EA em comunidades seguidos por aqueles referentes à EA nos espaços formais de ensino. Podemos perguntar se o fato de a ANPPAS agregar os PPGs multidisciplinares ambientais e a ANPED, os PPGs em educação, pode estar relacionado a essas diferentes ênfases nos trabalhos de pesquisa. Contudo, qualquer afirmação a esse respeito não seria conclusiva.

No EPEA, o panorama temático se mostrou diferente dos dois outros eventos. Surpreendentemente, o tema mais expressivo quando tomado isoladamente foi os sentidos da $\mathrm{E} A$, mostrando uma preocupação acentuada com uma dimensão que poderíamos chamar, no sentido amplo, 
de "semiótica" da EA, mas que também pode estar relacionada à grande quantidade de trabalhos buscando investigar certos conceitos ambientais para grupos específicos, uma estratégia de pesquisa que se tornou muito popular entre os trabalhos dos pesquisadores mais jovens da EA. O ensino formal e a formação de professores formam também um forte núcleo de preocupações. Vale a pena destacar que o tema Fundamentos da EA, que aparece em quarto lugar, com 27 trabalhos - resultado não muito expressivo no cômputo geral -, mantém-se entre 7 e 6 trabalhos nas edições de 2001 e 2003 e salta para 14 trabalhos em 2005, mostrando um aumento da presença de uma discussão teórica e conceitual entre os trabalhos da terceira edição do EPEA.

Em síntese, poderíamos dizer que os temas que mais se evidenciaram por evento foram a discussão teórico-metodológica na ANPED, a EA popular na ANPPAS e os sentidos da EA no EPEA. Contudo, quando agregamos as temáticas, podemos ver que a preocupação com a EA nos espaços formais de ensino foi uma constante nos três eventos. Em todos eles, os temas menos recorrentes ficaram por conta das categorias $E A$ na cultura, EA no debate ambiental e EA e a temática identidade/subjetividade. Evidentemente, a pequena expressão quantitativa das temáticas anteriormente citadas não significa que sejam em si irrelevantes ou que não tenham seus nichos de pesquisadores produzindo eventos e trabalhos nessas direções. Um exemplo é o grupo de pesquisa da educação da UFSC, "Grupo Tecendo - Educação Ambiental e Estudos Culturais", que atua na área de educação ambiental e estudos culturais, a qual já conta com uma linha de pesquisa consistente há alguns anos ${ }^{16}$. Do mesmo modo, se fôssemos analisar eventos de psicologia que abrigam GTs de psicologia ambiental, a temática identidade/subjetividade relacionada ao meio ambiente provavelmente iria aparecer com maior evidência, pois se trata de temáticas constitutivas da psicologia social, dentro da qual a psicologia ambiental vem se constituindo como uma subárea ${ }^{17}$. Atribuímos a menor evidência

16 O "Grupo Tecendo - Educação Ambiental e Estudos Culturais" recentemente lançou uma página voltada para a difusão de pesquisas e artigos dentro da temática EA e estudos culturais, disponível em: http://www.grupotecendo.com.br/. Nela se pode ver a trajetória dessa iniciativa.

17 O desenvolvimento da psicologia ambiental associada aos institutos ou departamentos de psicologia social pode ser observado na formação de grupos e laboratórios de pesquisa 
dessas temáticas como indicativo do caráter emergente do diálogo das suas áreas de origem - a psicologia social de abordagem sócio-histórica e os estudos culturais - com a educação ambiental.

\section{Considerações finais}

Até o momento, nos parece sustentável afirmar que a progressiva constituição da educação ambiental enquanto uma área de produção de conhecimento científico tem se produzido principalmente na confluência dos campos da educação e de um segmento das ciências humanas ambientais que poderíamos denominar como o fez a ANPPAS: "ambiente e sociedade". Do mesmo modo, podemos observar aí a construção das condições de legitimação de um profissional ambiental, especificamente do/a educador/a ambiental, caracterizado/a pela interdisciplinaridade dos saberes ambientais. Nesses saberes ambientais da EA, é importante considerar a predominância do corte socioambiental e humanístico e, em menor escala, dos saberes técnicos ambientais, como os provenientes das ciências da Terra e das ciências exatas, situação também identificada por Lorenzetti e Delizoicov (2007, p. 13) ${ }^{18}$. Esse profissional, mesmo sendo formado dentro de um ambiente auto e heteroproclamado interdisciplinar, tem obtido progressivo reconhecimento na sociedade e no campo acadêmico como porta-voz legítimo da esfera educativa do campo ambiental. Tomando por base a teoria dos campos sociais de Bourdieu (2004), poderíamos indagar: como esse profissional seguirá se firmando como legítimo especialista de uma área com certa especificidade que tem, ao mesmo tempo, o desafio da interdisplinaridade? Um profissional educador ambiental ou um pesquisador que adota a educação ambiental como uma temática interdisciplinar na qualidade de seu objeto de

em Psicologia Ambiental nas últimas décadas nas universidades que foram pioneiras nessa área de estudos, como o Grupo de Psicologia Ambiental da UFRN. http://www.meioambiente.ufrn.br; o laboratório de psicologia ambiental na UNB http://www.psi-ambiental.net/ e o Laboratório de Psicologia Socioambiental da USP http:// www.lapsi.usp.br.

18 Lorenzetti (2007, p. 13), em seu estudo sobre dissertações e teses defendidas sobre EA entre 1981 e 2003, classificou 55,5\% destas como pertencentes à área de Ciências Humanas e outras (Ensino), segundo as categorias utilizadas pelo CNPq para as áreas do conhecimento. 
pesquisa? Especialmente em situações de crise, como vimos recentemente nas discussões da Rede Brasileira de EA ao definir sua nova coordenação e articulação com outras instâncias da política ambiental, parece firmar-se o pólo da identidade profissional de educador/a ambiental ${ }^{19}$. Em outros momentos de caráter acadêmico/reflexivo e mais distantes das urgências da ação política, tende a emergir o pólo da EA como área de estudo interdisciplinar. Essa é uma tensão que, acreditamos, seguirá vigente ainda por muito tempo, e apenas a observação dos processos históricos que virão poderá sugerir em que direção a educação ambiental se consolidará.

Nosso objetivo nesta pesquisa foi, sobretudo, iniciar um monitoramento do perfil dos trabalhos apresentados nos principais eventos de pesquisa em EA no Brasil, oferecendo subsídios para que outros pesquisadores possam retomar esses dados e mesmo lançar outras hipóteses além das aqui levantadas.

Reconhecemos a necessidade de continuar monitorando esses eventos e de criar uma série histórica, o que nos ajudaria a ver, no decorrer de um tempo mais amplo, mudanças e tendências no perfil de pesquisadores e trabalhos, bem como a avaliar possíveis relações entre as direções das pesquisas e as políticas públicas de educação e meio ambiente. Sabemos que nesta pesquisa apenas iniciamos esse esforço e seria importante juntá-lo a outras iniciativas na mesma direção. Dado o relativo pouco tempo de existência desses espaços de pesquisa em EA, temos a oportunidade de seguir seus desdobramentos desde o início de sua institucionalização, oferecendo um perfil da produção de conhecimento em EA que, certamente, não traduz todo o cenário brasileiro, que é muito mais amplo, mas pelo menos articula espaços representativos desse universo, a partir dos quais podemos acompanhar as mudanças do campo educativo e ambiental e os processos de legitimação de um saber da e sobre a educação ambiental ao longo do tempo.

\footnotetext{
19 Houve momentos no segundo semestre de 2008 em que se chegaram a discutir na lista de facilitação da REBEA propostas para regulamentar os princípios da EA de modo que se definisse quem poderia ou não ser considerado educador/a ambiental. Na mesma direção, também se chegou a cogitar o estabelecimento de uma organização semelhante a um conselho profissional desse educador/a. Essas propostas foram combatidas na lista de discussão da REBEA, mas sua emergência e a discussão que provocaram foram significativas da tensão identitária que segue latente na educação ambiental.
} 


\section{Referências}

ANPEDSUL - SEMINÁRIO DE PESQUISA EM EDUCAÇÃO DA REGIÃO SUL, 5., 2006, Santa Maria. Anais... Santa Maria: 2006. 1 CD.

AVANZI, Maria Rita; SILVA, Rosana Louro Ferreira. Traçando os caminhos da pesquisa em educação ambiental: uma reflexão sobre o II EPEA. Quaestio, Revista de Estudos de Educação, Sorocaba, v. 1, n. 1, p. 123-132, maio 1999.

BOURDIEU, Pierre. Os usos sociais da ciência: por uma sociologia clínica do campo científico. São Paulo: Editora UNESP, 2004.

CAVALARI, Rosa Maria Feiteiro; SANTANA, Luiz Carlos; CARVALHO, Luiz Marcelo. Concepções de educação e Educação Ambiental nos trabalhos do I EPEA. Pesquisa em Educação Ambiental, v. 1, n. 1, p. 141-173, jul./dez. 2006.

COLÓQUIO DE PESQUISADORES EM EDUCAÇÃO AMBIENTAL DA REGIÃO SUL, 1., 2004, Itajaí. Anais... Pesquisa em Educação Ambiental: Pensamentos e Reflexões de Pesquisadores em Educação Ambiental. Pelotas: Ed. Universitária/ UFPel, 2004.

COSTA, Marisa Cristina Vorraber. O magistério e a política cultural de representação e identidade. In: (Org.). O magistério na politica cultural. Canoas: ULBRA, 2006. p. 6992.

ENCONTRO DA ASSOCIAÇÃO NACIONAL DE PÓS-GRADUAÇÃO E PESQUISA EM AMBIENTE E SOCIEDADE, 1., 2002, Indaiatuba. Campinas: ANPPAS. 1 CD.

ENCONTRO DA ASSOCIAÇÃO NACIONAL DE PÓS-GRADUAÇÃO E PESQUISA EM AMBIENTE E SOCIEDADE, 2., 2004, Indaiatuba. Campinas: ANPPAS. 1 CD.

ENCONTRO DE PESQUISA EM EDUCAÇÃO AMBIENTAL, 2., 2003, São Carlos. Programa e Caderno de Resumos. São Carlos: UFSCar, 2003.

ENCONTRO DE PESQUISA EM EDUCAÇÃO AMBIENTAL, 3., 2005, Ribeirão Preto. Caderno de Resumos e Programação. Ribeirão Preto: Faculdade de Filosofia, Ciências e Letras/USP, 2005.

ENCONTRO DE PESQUISA EM EDUCAÇÃO AMBIENTAL, 4., 2007, Rio Claro. Resumos e Caderno de Programação. Rio Claro: Instituto de Biociências/UNESP, 2007.

ENCONTRO DE PESQUISA EM EDUCAÇÃO AMBIENTAL: tendências e perspectivas, 2001, Rio Claro. Anais... Rio Claro: Revista Educação: Teoria e Prática, v. 9, n. 16/17, 2001.

FREITAS, Denise de; OLIVEIRA, Haydée Torres de. Pesquisa em Educação Ambiental: um panorama de suas tendências metodológicas. Pesquisa em Educaşão Ambiental, v. 1, n. 1, p. 175-191, jul./dez. 2006.

INSTITUTO BRASILEIRO DE GEOGRAFIA E ESTATÍSTICA. Sintese de indicadores sociais: uma análise das condições de vida da população brasileira; 2007. Rio de Janeiro: IBGE, 2007. 255 p. ilus. (Estudos \& Pesquisas. Informação Demográfica e Socioeconômica, 21).

KAWASAKI, Clarice Sumi, MATOS, Mauricio dos Santos e MOTOKAME, Marcelo Tadeu. O perfil inicial do pesquisador em Educação Ambiental: elementos para o estudo 
sobre a constituição de um campo de pesquisa em EA. Pesquisa em Educação Ambiental, v. 1, n. 1, jul./dez. 2006.

LORENZETTI, Leonir. Estilos de Pensamento em Educação Ambiental: uma Análise a Partir das Dissertações e Teses. 2008. Tese (Doutorado em Educação Científica e Tecnológica) Universidade Federal de Santa Catarina, Florianópolis.

LORENZETTTI, Leonir; DELIZOICOV, Demétrio. A produção acadêmica brasileira em educação ambiental.. In: CONGRESO EUROPEO CEISAL DE LATINOAMERICANISTAS, 5., 2007, Bruxelas. Anais eletrônicos... Bruxelas: 2007. Disponível em: <http://www.reseau-amerique-latine.fr/ceisal-bruxelles/CyT-MA/CyTMA-2-Lorenzetti.pdf>. Acesso em: 26 fev. 2009.

LOUREIRO, Carlos Frederico Bernardo. O Primeiro Ano do GT Educação Ambiental da Associação Nacional de Pós-Graduação e Pesquisa em Educação (ANPED): um Convite à Reflexão. Educação e Cultura Contemporânea, Rio de Janeiro, v. 3, n. 5, jan./jun. 2006.

NOVICKI, Victor. Abordagens teórico-metodológicas na pesquisa discente em EA do GE 22. In: ASSOCIAÇÃO NACIONAL DE PÓS-GRADUAÇÃO E PESQUISA EM EDUCAÇÃO, 26., 2003, Poços de Caldas. Anais... Poços de Caldas, 2003.

RAMOS, Marcelo Valente; GUERRA, Antonio Fernando Silveira; GAZZONI, Castello. Análise de trabalhos de Educação Ambiental da Anped - uma visão segmentada das categorias de pesquisa em EA. In: ENCONTRO DE PESQUISA EM EDUCAÇÃO AMBIENTAL, 3., 2005, Ribeirão Preto. Resumos... Ribeirão Preto: FFCLRP, 2005. 1 CD.

SAITO, Carlos Hiroo; BASTOS, Fábio da Purificação; ABEGG, Ilse. Temáticas Ambientais e Biomas Brasileiros: Análise dos Trabalhos de Pesquisa em Educação em Ciências em Eventos Científicos Nacionais nos Últimos Cinco Anos. Revista Eletrônica do Mestrado em Educação Ambiental, v. 17, p. 167-177, jul./dez. 2006.

SEMINÁRIO DE PESQUISA EM EDUCAÇÃO DA REGIÃO SUL, 5., 2004, Curitiba. Anais... Curitiba: PUCPR, 2004.

SIMPÓSIO SUL BRASILEIRO DE EDUCAÇÃO AMBIENTAL, 1.; SIMPÓSIO GAÚCHO DE EDUCAÇÃO AMBIENTAL - SIGEA, 2.; SEMANA ALTO URUGUAI DO MEIO AMBIENTE - SAUMA, 14., 2002. Diversidade na educação ambiental: olhares e cores. Erechim: EdiFAPES, 2002.

WERLE, Flávia Obino Corrêa. Práticas de gestão e feminização do magistério. Cadernos de Pesquisa, São Paulo, v. 35, n. 126, p. 609-634, 2005. Disponível em: <http://www. scielo. br/scielo.php?pid $=$ S010015742005000300005\&script $=$ sci_abstract\&tlng $=\mathrm{pt}>$. Acesso em: 10 jul. 2008

Artigo: recebido em 19/08/2008 - aprovado em 22/12/2008 